\section{Prevalence of comorbidities and risk factors in spondyloarthritis: results of a cross- sectional study}

Spondyloarthritis (SpA) includes axial and peripheral SpA, according to the Assessment of SpondyloArthritis international Society classification criteria. ${ }^{12}$ An increasing number of research has focused on the comorbidities and risk factors in SpA. The first and latest international cross-sectional ASASCOMOSPA study, published in the Annals of the Rheumatic Diseases, has proposed some comorbidities such as cardiovascular diseases, osteoporosis, cancers, infections and gastrointestinal diseases. This research has also proposed the risk factors for cardiovascular diseases, cancers and osteoporosis. ${ }^{3}$ Other studies have also focused on the cardiovascular diseases among patients with SpA. ${ }^{4-6}$ However, as for heart comorbidities, valvular heart disease was not mentioned in the ASAS-COMOSPA study, while it has been reported to be associated with SpA in a number of recent studies, based both on epidemiology and pathology. ${ }^{7-9}$ As for risk factors for cardiovascular diseases, hyperuricaemia was not included as well, while uric acid has also been proven to be related to cardiovascular disease in the recent years. ${ }^{10-13}$ Since there are still some comorbidities and risk factors to be evaluated, we proposed a research to include valvular heart disease as a comorbidity of $\mathrm{SpA}$ and hyperuricaemia as a risk factor of cardiovascular disease among patients with SpA.

From 2016 to 2018, we conducted a cross-sectional study of 202 SpA diagnosed by rheumatologists in the Chinese Shenzhen Second People's Hospital. We extracted data from the hospital's information systems by searching medical files at the Department of Rheumatology and Immunology, the Department of Ophthalmology, and the Department of Gastroenterology. All the medical files were examined to see if the diagnosis of axial or peripheral SpA could be confirmed.

Once the diagnosis of axial and peripheral SpA was confirmed, the following categories of data were collected: demographics and disease characteristics, extra-articular manifestations, comorbidities, risk factors for comorbidities, and sacroiliac joint image. The Bath Ankylosing Spondylitis Disease Activity Index,${ }^{14}$ the Ankylosing Spondylitis Disease Activity Score calculated with CRP, ${ }^{15}{ }^{16}$ and the Bath Ankylosing Spondylitis Functional Index were collected. ${ }^{17}$ Medications including nonsteroidal anti-inflammatory drug (NSAID), corticosteroids, conventional synthetic disease-modifying antirheumatic drugs (DMARDs) and tumour necrosis factor inhibitor (TNFi) were also collected. Extra-articular manifestations included uveitis, psoriasis and inflammatory bowel disease (IBD) (Crohn's/ulcerative colitis). Comorbidities included cardiovascular disease, diabetes, valvular heart disease and gout. Risk factors for comorbidities of cardiovascular disease included smoking, hypertension, hyperuricaemia and hyperlipidaemia. Hypertension was defined as a history of hypertension or antihypertensive therapy or blood pressure (BP) $>140 / 90 \mathrm{~mm} \mathrm{Hg}$, or BP $>130 / 80 \mathrm{~mm} \mathrm{Hg}$ in the case of history of diabetes or renal insufficiency. Hyperuricaemia was defined as uric acid $>416 \mu \mathrm{mol} / \mathrm{L}$ in men and $>357 \mu \mathrm{mol} / \mathrm{L}$ in women. ${ }^{18-20}$ Hyperlipidaemia included factors of triglycerides, low-density lipoprotein (LDL) cholesterol and total cholesterol. ${ }^{3}{ }^{12}$ Sacroiliac joint image was evaluated as radiographic SpA or non-radiographic SpA. Radiographic SpA was defined as grade II bilaterally or grade III-IV unilaterally, according to the Modification of the New York Criteria for radiography. ${ }^{21}$ It can also be defined as an erosion score and/or
334 patients who meet the diagnostic criteria for axial or peripheral spondyloarthritis

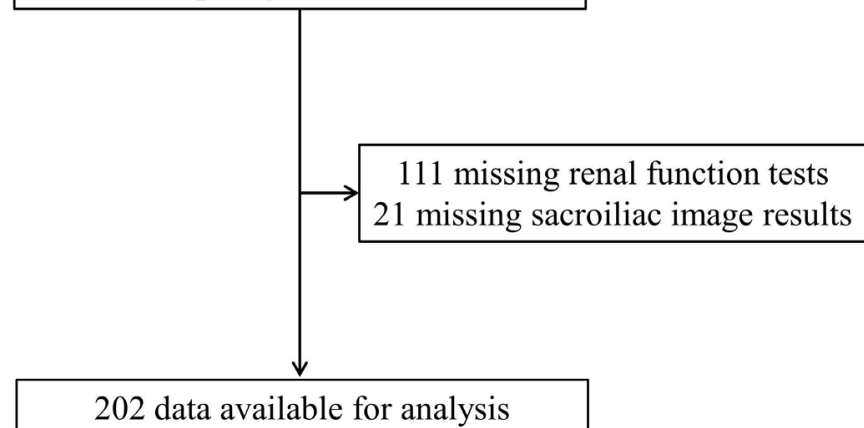

Figure 1 Study profile.

joint space score of 2 or higher in any of the 24 regions of both joints for CT. ${ }^{22}$ Non-radiographic SpA was defined as sacroiliac joint image without structural sacroiliitis described above. ${ }^{23}$ Data were analysed with the use of the statistical packages $\mathrm{R}$

\begin{tabular}{|c|c|}
\hline Number of patients & 202 \\
\hline Age (years) & $38.2 \pm 12.6$ \\
\hline Gender (male) & $147(72.8 \%)$ \\
\hline HLA-B27 & $177(88.9 \%)$ \\
\hline Smoking status (current) & $35(17.3 \%)$ \\
\hline Smoking status (ever) & $39(19.3 \%)$ \\
\hline Alcohol & $27(13.4 \%)$ \\
\hline Disease duration (months) & $87.5 \pm 86.6$ \\
\hline Uric acid (umol/L) & $380.2 \pm 107.7$ \\
\hline BASDAI & $3.3 \pm 1.9$ \\
\hline ASDAS-CRP & $2.6 \pm 1.1$ \\
\hline BASFI (0-10) & $1.8 \pm 2.2$ \\
\hline Axial involvement (any) & $181(89.6 \%)$ \\
\hline Peripheral involvement (any) & $104(51.5 \%)$ \\
\hline Axial involvement (only) & $103(51.0 \%)$ \\
\hline Peripheral involvement (only) & $25(12.4 \%)$ \\
\hline Mixed (axial and peripheral involvement) & $84(41.6 \%)$ \\
\hline Enthesitis involvement & $25(12.4 \%)$ \\
\hline Dactylitis & $9(4.5 \%)$ \\
\hline Uveitis & $35(17.3 \%)$ \\
\hline Psoriasis & $10(5.0 \%)$ \\
\hline $\mathrm{IBD}$ & $4(2.0 \%)$ \\
\hline Diarrhoea & $21(10.4 \%)$ \\
\hline NSAID (ever) & $107(53.0 \%)$ \\
\hline Corticosteroids (past) & $27(13.4 \%)$ \\
\hline Conventional synthetic DMARDs (past) & $49(24.3 \%)$ \\
\hline TNFi (past) & $21(10.4 \%)$ \\
\hline Conventional synthetic DMARDs (onset) & $53(26.2 \%)$ \\
\hline TNFi (onset) & $63(31.2 \%)$ \\
\hline
\end{tabular}

All results are presented as mean \pm SD for continuous variables and percentages for categorical variables.

ASDAS, Ankylosing Spondylitis Disease Activity Score-CRP; BASDAI, Bath Ankylosing Spondylitis Disease Activity Index; BASFI, Bath Ankylosing Spondylitis Functional Index; CRP, C reactive protein; DMARDs, disease-modifying antirheumatic drugs; HLA-B27, human leucocyte antigen B27; IBD, inflammatory bowel disease; NSAID, non-steroidal anti-inflammatory drug; TNFi, tumour necrosis factor inhibitor. 


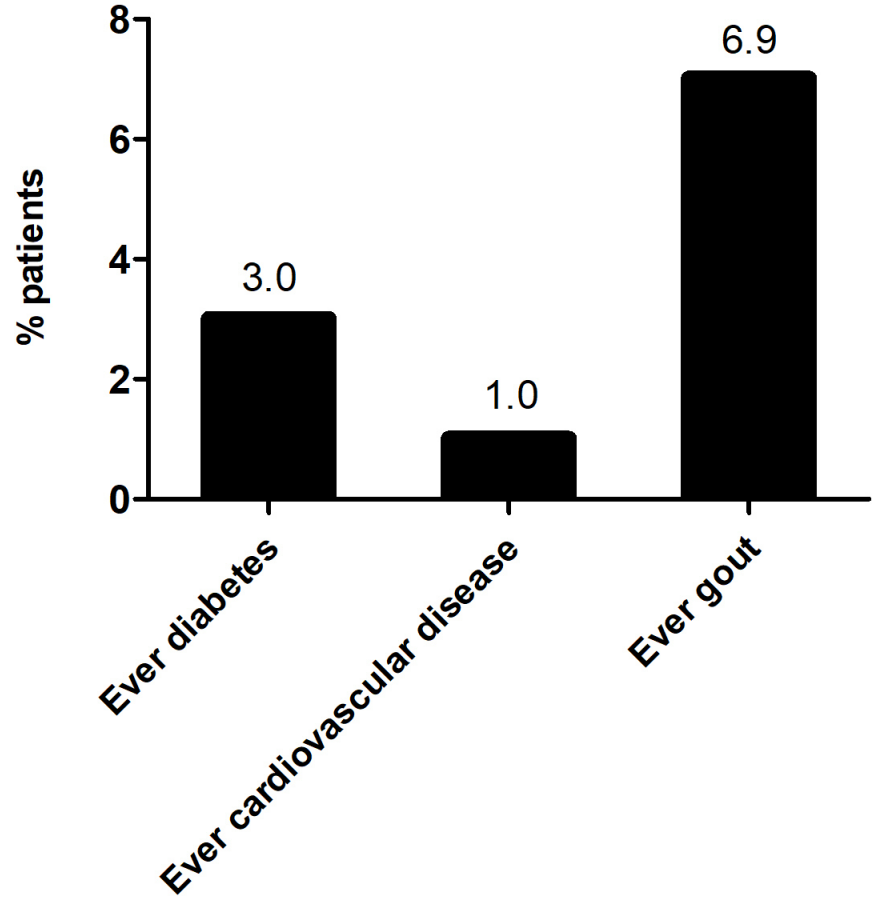

Figure 2 Prevalence of comorbidities.

(The R Foundation; http://www.r-project.org; version 3.4.3) and EmpowerStats (www.empowerstats.com; X\&Y Solutions Inc).

Between 1 January 2016 and 31 December 2018, 202 individuals were included in this study. Individuals who were not examined for renal function $(n=111)$ and those who were not examined for sacroiliac joint imaging $(n=21)$ were not included. The study profile of screening patients for analysis is presented in figure 1.

The demographics and disease characteristics are listed in table 1. More patients presented axial involvement (89.6\%), and fewer patients presented only peripheral involvement (12.4\%). More patients ever accepted NSAIDs (53.0\%), and fewer accepted TNFi (10.4\%) compared with conventional synthetic DMARDs (24.3\%). However, more and more patients began to

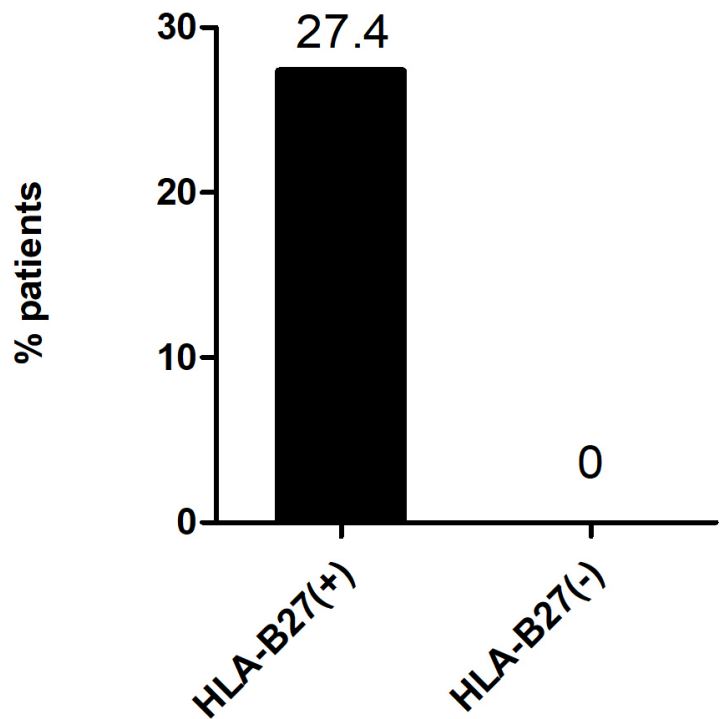

Figure 3 Valvular heart disease in HLA-B27-positive and HLA-B27negative subgroups. HLA-B27, human leucocyte antigen B27.

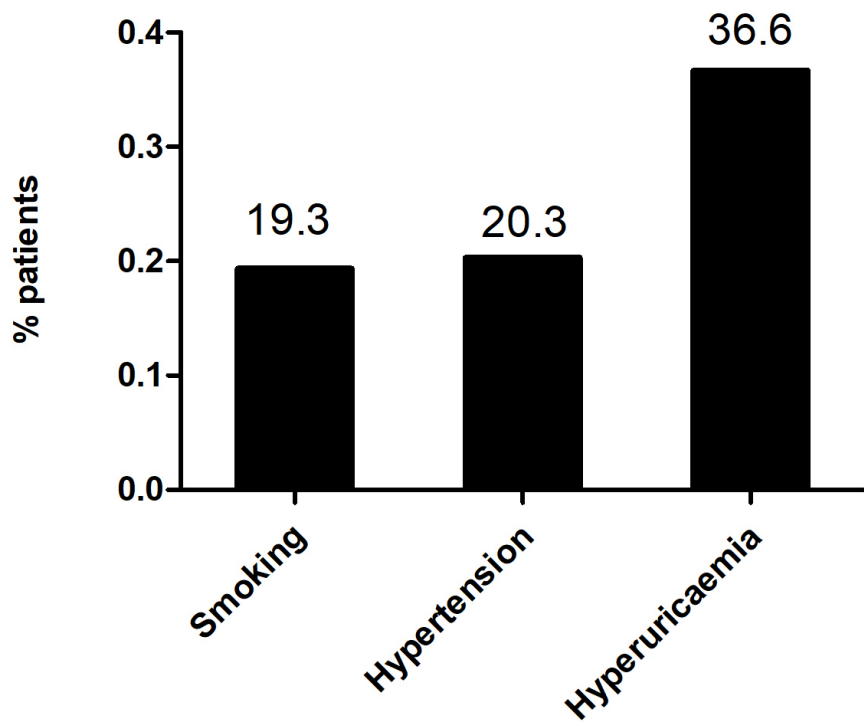

Figure 4 Prevalence of detected risk factors for comorbidities.

accept TNFi (31.2\%) as an optimal therapy, instead of conventional synthetic DMARDs (26.2\%).

The most common extra-articular manifestation was uveitis (17.3\%), while the least common was IBD (2.0\%). Diarrhoea was relatively frequent, which was $10.4 \%$ of the study population.

The prevalence of comorbidities is presented in figure 2 . The prevalence of cardiovascular disease in the study population was $1.0 \%$, while that of diabetes was $3.0 \%$. Of the patients $6.9 \%$ ever suffered gout. Cardiac ultrasonography evaluation was performed on 124 of the 202 patients, and the prevalence of valvular heart disease in this population was $24.2 \%$. When evaluated by human leucocyte antigen B27 (HLA-B27)-positive and HLA-B27-negative subgroups, respectively, HLA-B27-positive subgroup presented more patients suffering from valvular heart disease $(27.4 \%)$, which had statistical significance $(p=0.014)$. This is presented in figure 3 .

The prevalence of detected risk factors for comorbidities is presented in figure 4. Conventional risk factors for cardiovascular disease (ie, BP, LDL cholesterol) were detected in this study. Of the patients in this study, 19.3\% ever smoked, $20.3 \%$ reported to have ever suffered from hypertension, $36.6 \%$ had hyperuricaemia, and 30.8\% had hyperlipidaemia (hyperlipidaemia detection was conducted in a scope of 133 patients).

Uric acid, a specific risk factor, was evaluated in this study with a mean \pm SD of $380.2 \pm 107.7 \mathrm{umol} / \mathrm{L}$. Uric acid was evaluated by radiographic SpA and non-radiographic SpA, with the radiographic subgroup $(n=141,69.8 \%)$ presenting a mean $\pm S D$ of $397.7 \pm 106.6 \mathrm{umol} / \mathrm{L}$ and the non-radiographic subgroup $(\mathrm{n}=61,30.2 \%)$ presenting a mean \pm SD of $339.8 \pm 99.8 \mathrm{umol} / \mathrm{L}$, which had statistical significance $(\mathrm{p}<0.001)$. The prevalence of hyperuricaemia in the radiographic SpA subgroup was $40.4 \%$, while in the non-radiographic SpA subgroup was 27.9\%; these are all presented in figure 5 .

Our study represents the characteristics of Chinese SpA population and reports some unnoticed and specific aspects, as a supplement to ASAS-COMOSPA study.

Although there were a lot of common demographics and disease characteristics of SpA presenting in this study as the ASAS-COMOSPA study, there were noteworthy aspects in extraarticular manifestation, comorbidities, risk factors for comorbidities and sacroiliac joint image. 


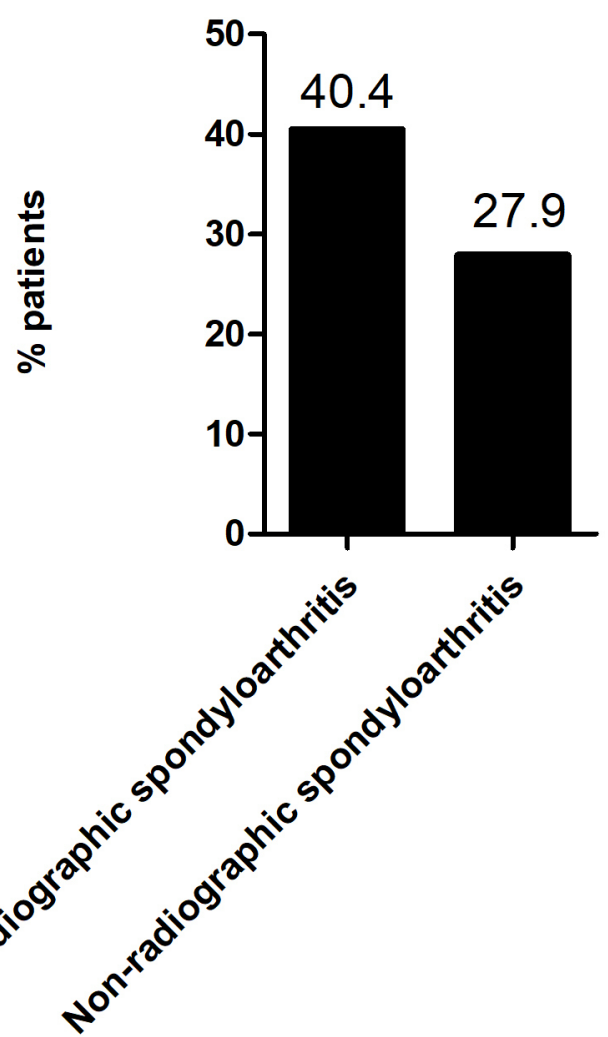

Figure 5 Prevalence of hyperuricaemia in radiographic spondyloarthritis and non-radiographic spondyloarthritis subgroups.

IBD was less common in Chinese population compared with the worldwide population shown in the ASAS-COMOSPA study. Diarrhoea was a frequent symptom of IBD. In this study of Chinese population $10.4 \%$ had diarrhoea, while diarrhoea was not mentioned in the ASAS-COMOSPA study. IBD was diagnosed using endoscopic and histological measures. As for reports about IBD, endoscopic manifestations were not consistent with symptoms such as diarrhoea and stool frequency. Endoscopically inactive disease was not associated with complete normalisation of diarrhoea. ${ }^{24}$ Diarrhoea, reflecting gut inflammation, ${ }^{25}$ was a noteworthy symptom of IBD among patients with SpA.

Valvular heart disease, which is also a common heart comorbidity of SpA, was relatively higher $(24.2 \%)$ in this study, compared with what has been reported in the heart failure population, ${ }^{26}$ which was also neglected by the ASASCOMOSPA study. The prevalence of valvular heart disease in HLA-B27-positive subgroup is different from that in the HLAB27-negative subgroup. We are going to discuss the association between valvular heart disease and HLA-B27 in a subsequent article. The prevalence of gout was higher in our study than the general population of most countries in the world. ${ }^{27}$

Uric acid, which had been proven to be a new cardiovascular risk factor, ${ }^{28} 29$ turned out to be relatively higher than the general population, ${ }^{30}$ and was different between the radiographic and non-radiographic subgroups. We will later discuss the association between uric acid and sacroiliac radiographic image in another article.

Further studies confirming the impact of comorbidities and risk factors in patients with $\mathrm{SpA}$ are required. If confirmed, these studies would lead to standardised assessments of patients with SpA.

Yupeng Lai $\odot,{ }^{1}$ Yanpeng Zhang, ${ }^{2}$ Shaozhen Mo, ${ }^{1}$ Jinsheng $\mathrm{Ma}^{3}$ Tongxin $\mathrm{Ni}^{4}{ }^{4}$ Zhihao Lei, ${ }^{5}$ Jun $\mathrm{Xia}^{6}{ }^{6}$ Chiduo $\mathrm{Xu}^{1}$
${ }^{1}$ Rheumatology and Immunology, Shenzhen Second People's Hospital, Shenzhen, Guangdong Province, China

'Laboratory, Shenzhen Second People's Hospital, Shenzhen, Guangdong Province, China

${ }^{3}$ Rehabilitation Medicine, Shenzhen Second People's Hospital, Shenzhen, Guangdong Province, China

${ }^{4}$ Cardiology, Shenzhen University General Hospital, Shenzhen, Guangdong Province, China

${ }^{5}$ Neurology, Shenzhen Second People's Hospital, Shenzhen, Guangdong Province, China

${ }^{6}$ Radiology, Shenzhen Second People's Hospital, Shenzhen, Guangdong Province, China

Correspondence to Dr Yupeng Lai, Rheumatology and Immunology, Shenzhen Second People's Hospital, Shenzhen 518035, China;

laiyupeng8811@126.comProfessor Jun Xia; xiajun@email.szu.edu.cnProfessor Chiduo Xu:

fsmyk17@163.com

Acknowledgements We are very grateful to the engineers of the medical information system.

Contributors $Y L$ and $C X$ designed the research protocol. SM, JM and TN extracted data from the medical files in the information system and interpreted the data. YZ extracted data from the laboratory system. YL and JX extracted data from the image system and evaluated the sacroiliac CT images. YL, YZ and ZL performed the statistical analysis. YL, YZ and JX wrote the manuscript. YL, YZ, JX and CX approved the version submitted.

Funding The authors have not declared a specific grant for this research from any funding agency in the public, commercial or not-for-profit sectors.

Competing interests None declared.

Patient and public involvement The study was a retrospective research that extracted data from a hospital's information system and did not involve patients in the design, recruitment and conduct of the study. The results of the study will be disseminated to all patients with SpA for better therapy after publication.

Patient consent for publication Not required.

Ethics approval The study was approved by the Ethics Committee of Shenzhen Second People's Hospital, with approval ID 20200224001.

Provenance and peer review Not commissioned; internally peer reviewed. (C) Author(s) (or their employer(s)) 2020. No commercial re-use. See rights and permissions. Published by BMJ.

$Y L$ and $Y Z$ contributed equally.

\section{Check for updates}

To cite Lai Y, Zhang Y, Mo S, et al. Ann Rheum Dis Epub ahead of print: [please include Day Month Year]. doi:10.1136/annrheumdis-2020-217313

Received 8 March 2020

Revised 18 March 2020

Accepted 18 March 2020

Ann Rheum Dis 2020;0:1-4. doi:10.1136/annrheumdis-2020-217313

ORCID iD

Yupeng Lai http://orcid.org/0000-0002-3503-4986

\section{REFERENCES}

1 Rudwaleit M, van der Heijde $D$, Landewé $R$, et al. The assessment of spondyloarthritis International Society classification criteria for peripheral spondyloarthritis and for spondyloarthritis in general. Ann Rheum Dis 2011;70:25-31.

2 Rudwaleit M, Landewé $R$, van der Heijde $D$, et al. The development of assessment of spondyloarthritis International Society classification criteria for axial spondyloarthritis (Part I): classification of paper patients by expert opinion including uncertainty appraisal. Ann Rheum Dis 2009;68:770-6.

3 Moltó A, Etcheto A, van der Heijde D, et al. Prevalence of comorbidities and evaluation of their screening in spondyloarthritis: results of the International cross-sectional ASAS-COMOSPA study. Ann Rheum Dis 2016;75:1016-23.

4 Essers I, Stolwijk C, Boonen A, et al. Ankylosing spondylitis and risk of ischaemic heart disease: a population-based cohort study. Ann Rheum Dis 2016;75:203-9.

5 Vinsonneau U, Brondex A, Mansourati J, et al. Cardiovascular disease in patients with spondyloarthropathies. Joint Bone Spine 2008;75:18-21.

6 Heeneman S, Daemen MJAP. Cardiovascular risks in spondyloarthritides. Curr Opin Rheumatol 2007;19:358-62. 
7 Bengtsson K, Forsblad-d'Elia H, Lie E, et al. Risk of cardiac rhythm disturbances and aortic regurgitation in different spondyloarthritis subtypes in comparison with general population: a register-based study from Sweden. Ann Rheum Dis 2018;77:541-8.

8 Ntari L, Sakkou M, Chouvardas P, et al. Comorbid TNF-mediated heart valve disease and chronic polyarthritis share common mesenchymal cell-mediated aetiopathogenesis. Ann Rheum Dis 2018;77:926-34.

9 Vereecke L, Elewaut D. Tumour necrosis factor: out of my heart! Ann Rheum Dis 2018;77:793-4.

10 Kleber ME, Delgado G, Grammer TB, et al. Uric acid and cardiovascular events: a Mendelian randomization study. JASN 2015;26:2831-8.

11 Kuwabara M, Niwa K, Hisatome I, et al. Asymptomatic hyperuricemia without comorbidities predicts cardiometabolic diseases: five-year Japanese cohort study. Hypertension 2017;69:1036-44.

12 Sjöström L, Lindroos A-K, Peltonen $M$, et al. Lifestyle, diabetes, and cardiovascular risk factors 10 years after bariatric surgery. N Engl J Med 2004;351:2683-93.

13 Klauser AS, Halpern EJ, Strobl S, et al. Dual-Energy computed tomography detection of cardiovascular monosodium urate deposits in patients with gout. JAMA Cardiol 2019. doi:10.1001/jamacardio.2019.3201. [Epub ahead of print: 11 Sep 2019].

14 Garrett $\mathrm{S}$, Jenkinson T, Kennedy LG, et al. A new approach to defining disease status in ankylosing spondylitis: the Bath ankylosing spondylitis disease activity index. J Rheumatol 1994;21:2286-91.

15 Lukas C, Landewé R, Sieper J, et al. Development of an ASAS-endorsed disease activity score (ASDAS) in patients with ankylosing spondylitis. Ann Rheum Dis 2009:68:18-24.

16 van der Heijde D, Lie E, Kvien TK, et al. ASDAS, a highly discriminatory ASAS-endorsed disease activity score in patients with ankylosing spondylitis. Ann Rheum Dis 2009;68:1811-8.

17 Calin A, Garrett S, Whitelock H, et al. A new approach to defining functional ability in ankylosing spondylitis: the development of the Bath ankylosing spondylitis functional index. J Rheumatol 1994;21:2281-5.

18 Juraschek SP, Gelber AC, Choi HK, et al. Effects of the dietary approaches to stop hypertension (DASH) diet and sodium intake on serum uric acid. Arthritis Rheumatol 2016:68:3002-9.
19 Rai SK, Fung TT, Lu N, et al. The dietary approaches to stop hypertension (DASH) diet, Western diet, and risk of gout in men: prospective cohort study. BMJ 2017;357:j1794.

20 Dubreuil M, Zhu Y, Zhang Y, et al. Allopurinol initiation and all-cause mortality in the general population. Ann Rheum Dis 2015;74:1368-72.

21 van der Linden S, Valkenburg HA, Cats $A$. Evaluation of diagnostic criteria for ankylosing spondylitis. A proposal for modification of the new York criteria. Arthritis Rheum 1984;27:361-8.

22 Diekhoff T, Hermann K-GA, Greese J, et al. Comparison of MRI with radiography for detecting structural lesions of the sacroiliac joint using $\mathrm{CT}$ as standard of reference: results from the SIMACT study. Ann Rheum Dis 2017;76:1502-8.

23 Melchior J, Azraq Y, Chary-Valckenaere I, et al. Radiography, abdominal CT and MRI compared with sacroiliac joint CT in diagnosis of structural sacroiliitis. Eur J Radiol 2017;95:169-76

24 Colombel J-F, Keir ME, Scherl A, et al. Discrepancies between patientreported outcomes, and endoscopic and histological appearance in UC. Gut 2017;66:2063-8.

25 Westreich ST, Ardeshir A, Alkan Z, et al. Fecal metatranscriptomics of macaques with idiopathic chronic diarrhea reveals altered mucin degradation and fucose utilization. Microbiome 2019;7:41.

26 Marciniak A, Glover K, Sharma R. Cohort profile: prevalence of valvular heart disease in community patients with suspected heart failure in UK. BMJ Open 2017;7:e012240.

27 Kuo C-F, Grainge MJ, Zhang W, et al. Global epidemiology of gout: prevalence, incidence and risk factors. Nat Rev Rheumatol 2015;11:649-62.

28 Kleber ME, Delgado G, Grammer TB, et al. Uric acid and cardiovascular events: a Mendelian randomization study. J Am Soc Nephrol 2015;26:2831-8.

29 Verdoia M, Barbieri L, Schaffer A, et al. Impact of diabetes on uric acid and its relationship with the extent of coronary artery disease and platelet aggregation: a single-centre cohort study. Metabolism 2014;63:640-6.

30 Zhang Y, Hou L-S, Tang W-W, et al. High prevalence of obesity-related hypertension among adults aged 40 to 79 years in Southwest China. Sci Rep 2019;9:15838. 